\title{
Enhancement of copper dispersion and catalytic performances in the hydrogenation of cinnamaldehyde by incorporation of aluminium into mesoporous SBA-15 silica
}

\author{
Adrian Ungureanu, ${ }^{*[a]}$ Alexandru Chirieac, ${ }^{[a]}$ Carmen Ciotonea, ${ }^{[a, b, c]}$ Irina Mazilu, ${ }^{[a, b]}$ Cezar \\ Catrinescu, ${ }^{[a]}$ Sabine Petit, ${ }^{[b]}$ Eric Marceau, ${ }^{*[c]}$ Sébastien Royer, ${ }^{[b, c]}$ and Emil Dumitriu ${ }^{[a]}$
}

Abstract: Copper is a base metal active in hydrogenation reactions, but it is difficult to disperse on mesostructured supports by conventional methods, with adverse consequences on the catalytic properties. Incorporating aluminium into ordered mesoporous SBA15 silicas via a simple two-step $\mathrm{pH}$-adjustment route allows solving the $\mathrm{Cu}$ dispersion and activity problems jointly. The incorporation of 20 wt.\% $\mathrm{Al}_{2} \mathrm{O}_{3}$ in the SBA-15 host structure leads to an increase of the copper metallic surface area by a factor 6 compared to the pure siliceous SBA-15-supported catalyst. The support also displays a high stability upon exposure to aqueous solutions, such as the impregnation solution, unlike ordered mesoporous alumina. Besides, Al introduction provides Lewis-acidic sites that favour the transformation of cinnamaldehyde into cinnamyl alcohol. As a consequence, the catalytic activity of materials prepared following this route is enhanced compared to a silica-supported system, while the chemoselectivity towards the unsaturated alcohol appears to be similar to that of a mesoporous alumina-supported system.

\section{Introduction}

Over the last two decades, copper-based nanostructured catalysts have attracted significant attention for hydrogenation reactions. ${ }^{1}$ However, the control over the size of copper nanoparticles (NPs) is often difficult, especially on mesostructured supports, when standard methods such as impregnation are used to introduce the metal. Populations of large copper NPs, with low dispersion, poor catalytic activity and poor stability, are usually reported in the final catalysts. ${ }^{2-10}$ Several strategies have been tested to stabilize copper nanoparticles (NPs) at sizes below $10 \mathrm{~nm}$ in mesostructured silicas: thermal treatments carried out at low pressures, ${ }^{11,12}$ modification of silicas by APTES grafting, ${ }^{2,13-15}$ impregnation using organic solvents ${ }^{16}$ or organometallic complexes, ${ }^{17}$ procedures based on self-induced assembly ${ }^{18}$ or deposition-

[a] Prof. A. Ungureanu, ${ }^{\star}$ Dr. A. Chirieac, Dr. C. Ciotonea, Dr. I. Mazilu, Dr. C. Catrinescu, Prof. E. Dumitriu

Faculty of Chemical Engineering and Environmental Protection "Gheorghe Asachi" Technical University of lasi - 73 D. Mangeron Bvd., 700050, lasi, ROMANIA

E-mail: aungureanu@tuiasi.ro

[b] Dr. I. Mazilu, Dr. C. Ciotonea, Dr. S. Petit, Prof. S. Royer IC2MP - Institut de Chimie des Milieux et Matériaux de Poitiers CNRS UMR 7285 CNRS - Université de Poitiers - 6 Rue Michel Brunet - TSA 51106, 86073 Poitiers Cedex 9, FRANCE

[c] Dr. C. Ciotonea, Dr. E. Marceau, ${ }^{*}$ Prof. S. Royer Univ. Lille, CNRS, Centrale Lille, ENSCL, Univ. Artois, UMR 8181 UCCS - Unité de Catalyse et de Chimie du Solide, F-59000 Lille, FRANCE

E-mail: eric.marceau@univ-lille1.fr precipitation, ${ }^{2,19-22}$ and decomposition of inorganic precursors by autocombustion. ${ }^{23}$ When standard impregnation procedures are used, it has been shown that the addition of second metals to copper (e.g., Ni, Cr), ${ }^{24-27}$ or the functionalization ${ }^{28,29}$ or pore occlusion of the mesostructured silica support by surfactants, ${ }^{27,30}$ promote copper dispersion, with a resulting increase of catalytic activity in the hydrogenation of cinnamaldehyde.

The hydrogenation of cinnamaldehyde (CNA) is known to be challenging as the unsaturated alcohol, cinnamyl alcohol (CNOL), should be selectively produced via $\mathrm{C}=\mathrm{O}$ bond hydrogenation. However, the preferred path on most catalysts, including silica-supported $\mathrm{Cu}$ systems, is the hydrogenation of the $\mathrm{C}=\mathrm{C}$ bond owing to favorable thermodynamics and lower activation barriers, ${ }^{30-34}$ While the literature on noble metals is abundant, fewer attempts have been made so far to develop a selective copper-based catalytic system. ${ }^{26,29,30,33-40}$ It was reported in particular that $\mathrm{Cu}^{+}$or $\mathrm{Cr}^{\delta+}$ sites adjacent to the active metallic $\mathrm{Cu}^{0}$ centers can function as electrophilic centers that polarize the $\mathrm{C}=\mathrm{O}$ bond via the lone electron pair in oxygen, thus improving the hydrogenation of the carbonyl group in CNA to CNOL, yet at low reaction rates. ${ }^{26,29}$ Previously, Marchi et al. reported that ternary $\mathrm{Cu}-\mathrm{Zn}-\mathrm{Al}$ and quaternary $\mathrm{Cu}-\mathrm{Ni}(\mathrm{Co})-$ $\mathrm{Zn}$-Al catalysts were one order of magnitude more active than $\mathrm{Cu} / \mathrm{SiO}_{2}$ in CNA hydrogenation, while selective towards CNOL. ${ }^{34}$ In these systems, $\mathrm{Cu}^{0}$ particles appeared as highly dispersed over a super-stoichiometric zinc aluminate spinel, and in close interaction with $\mathrm{M}^{2+}$ cations. On the other hand, it has been demonstrated that the introduction of $\mathrm{Al}$ atoms at the support surface has a positive effect on both the activity and chemoselectivity of Pt-based catalysts in the hydrogenation of CNA. ${ }^{41}$ The presence of Lewis sites onto which the CNA molecule adsorbs via its $\mathrm{C}=\mathrm{O}$ bond was key to improve the selectivity toward the unsaturated alcohol, without the intervention of a second transition metal.

It can thus be tempting to solve simultaneously the problem of catalytic activity on the one hand, by promoting copper dispersion thanks to strong metal-support interactions, and the problem of selectivity toward cinnamyl alcohol on the other hand, by providing surface Lewis sites with enhanced affinity for the $\mathrm{C}=\mathrm{O}$ bond. To this end, ordered mesoporous silica (OMS) supports can be modified by addition of aluminium (ordered mesoporous silica-aluminas, OMSA). A facile way to incorporate high amounts of aluminum into the structure of SBA-15 mesoporous silica is to combine the direct synthesis of silica in aqueous medium with $\mathrm{Al}$ introduction via a two-step $\mathrm{pH}$ adjustment method. ${ }^{42}$ This approach was successfully used to prepare AI-SBA-15 with a wide range of $\mathrm{Si} / \mathrm{Al}$ ratios $(130-5.2) .{ }^{43}$ Compared with 
siliceous SBA-15, short and long-range mesopore ordering and textural quality are retained, and the number of Lewis sites can be easily controlled.

Herein, we show that even if introduced by standard impregnation, monometallic copper can be stabilized as highly dispersed nanoparticles on water-stable AI-SBA-15 OMSA. We compare these catalysts with materials prepared on SBA-15 OMS and ordered mesoporous alumina (OMA) supports, to highlight the positive effect of aluminum incorporation on the catalyst performances, and we demonstrate that the combination of highly dispersed copper nanoparticles and presence of Al results in catalysts displaying a high activity and selectivity to cinnamyl alcohol.

\section{Results and Discussion}

\section{Structural, textural and surface characterization}

Al-SBA-15 supports (OMSA10, OMSA20) were prepared with $\mathrm{Al}_{2} \mathrm{O}_{3}$ contents of 10 and 20 wt. \% (Si/Al atomic ratio $=$ 7.7 and 3.4, respectively), while SBA-15 silica (OMS) and organized mesoporous alumina (OMA) were used as reference supports (experimental details are supplied in the final section of the article). The low-angle XRD patterns of OMSA supports (ESI, Figure S1) exhibit one well-resolved peak and two weak peaks assigned to (100), (110) and (200) reflections associated with hexagonal $p 6 \mathrm{~mm}$ symmetry of well-ordered mesostructured SBA-15. In line with our previous results, ${ }^{43}$ it can be seen that upon $\mathrm{Al}$ introduction via the $\mathrm{pH}$ adjustment method, the short- and long-range mesopore ordering and pore size of Al-SBA-15 materials are well preserved at high Al loadings, because the concentration of Al species is high enough to protect the mesoporous structure against hydrolytic degradation.
5 wt.\% copper was introduced by incipient wetness impregnation with an aqueous solution of copper nitrate on OMS and OMSA, or by melt infiltration of hydrated copper nitrate in the case of OMA. The choice of the latter procedure was made necessary by the high sensitivity of mesoporous aluminas to exposure to water ${ }^{47,48}$ ICP-OES analysis confirmed that $\mathrm{Al}_{2} \mathrm{O}_{3}$ and $\mathrm{Cu}$ contents were close to the targeted values (Table 1).

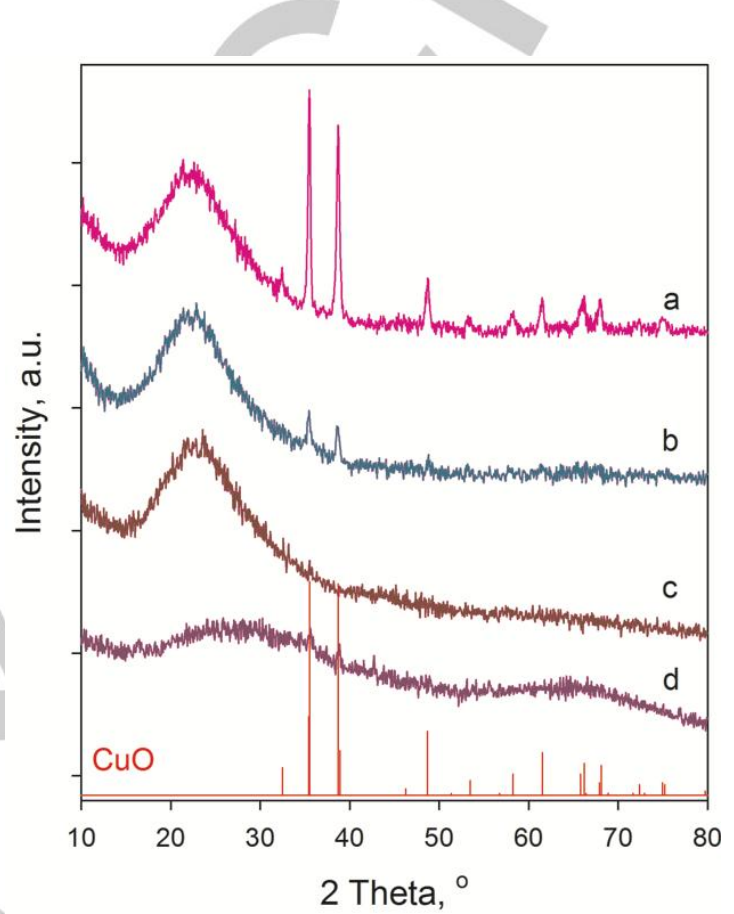

Figure 1. XRD patterns for Cu/OMS (a), Cu/OMSA10 (b), Cu/OMSA20 (c) and $\mathrm{Cu} / \mathrm{OMA}(\mathrm{d})$

Table 1. Physico-chemical properties for supports and copper containing materials

\begin{tabular}{|c|c|c|c|c|c|c|}
\hline \multirow[t]{2}{*}{ Sample } & \multicolumn{2}{|c|}{ ICP } & XRD & \multicolumn{3}{|c|}{$\mathrm{N}_{2}$ physisorption } \\
\hline & $\mathrm{Al}_{2} \mathrm{O}_{3}$, wt. $\%$ & $\mathrm{Cu}, \mathrm{wt} . \%$ & $\mathrm{D}_{\mathrm{XDD}}{ }^{[a]}, \mathrm{nm}$ & $\mathrm{S}_{\mathrm{BET}}{ }^{[\mathrm{b}]}, \mathrm{m}^{2} \mathrm{~g}^{-1}$ & $\mathrm{~V}_{\mathrm{p}}^{[\mathrm{c}]}, \mathrm{cm}^{3} \mathrm{~g}^{-1}$ & $\mathrm{D}_{\mathrm{p}}^{[\mathrm{d]}]}, \mathrm{nm}$ \\
\hline OMS & & & & 810 & 1.12 & 8.4 \\
\hline $\mathrm{Cu} / \mathrm{OMS}$ & & 4.6 & 31.5 & 725 & 1.07 & 8.2 \\
\hline OMSA10 & 9.1 & - & & 351 & 0.86 & 9.2 \\
\hline Cu/OMSA10 & & 4.4 & 17.0 & 323 & 0.79 & 9.1 \\
\hline OMSA20 & & & & 360 & 0.76 & 8.4 \\
\hline $\mathrm{Cu} / O M S A 20$ & & 4.4 & n.d. & 313 & 0.63 & 8.4 \\
\hline OMA & 100 & - & & 195 & 0.37 & 7.5 \\
\hline CU/OMA & & 4.9 & n.d. & 197 & 0.37 & 8.2 \\
\hline
\end{tabular}

[a] $\mathrm{D}_{\mathrm{XRD}}=\mathrm{CuO}$ crystallite size evaluated by Scherrer equation; [b] $\mathrm{S}_{\mathrm{BET}}=$ specific surface area obtained using the $\mathrm{BET}$ equation;

[c] $V_{p}=$ total pore volume at $P / P_{0}=0.97 ;[d] D_{p}=$ mean diameter of pores evaluated by NL-DFT for cylindrical pores/equilibrium model. 
Wide-angle XRD (WA-XRD) patterns of the calcined Cucontaining samples are presented in Figure 1. All the samples based on OMS and OMSA display a broad peak at $2 \theta \sim 24^{\circ}$ characteristic of amorphous silica. No diffraction peaks belonging to alumina can be observed in the diffractograms of OMSA-based systems, indicating a dispersed or amorphous state for aluminic species. The diffractogram of $\mathrm{Cu} / \mathrm{OMA}$ exhibits broad features assigned to poorly crystallized alumina.

Besides, the $\mathrm{Cu} / \mathrm{OMS}$ pattern presents intense and narrow diffraction peaks in the range $2 \theta=30-80^{\circ}$, characteristic of monoclinic CuO (ICDD 048-1548) (Figure 1a). These CuO crystallites are large (mean size of $31.5 \mathrm{~nm}$, estimated by the Scherrer equation), and thus located on the external surface of the support given the pore size of SBA-15 $(8.4 \mathrm{~nm})$. With the introduction of aluminium in the support (Cu/OMSA10), the diffraction peaks assigned to large $\mathrm{CuO}$ particles become much less intense and broader (Figure 1b), indicating that the average size of these crystallites has decreased $(17 \mathrm{~nm}$, see Table 1). For the sample with the highest amount of aluminium (Cu/OMSA20), no diffraction peaks can be observed. Copper phases are thus highly dispersed, at a size below the detection limit in XRD $(\sim 3 \mathrm{~nm})$. These results might be considered as first evidence of the positive role of the $\mathrm{Al}_{2} \mathrm{O}_{3}$ coating in improving the dispersion of copper species upon impregnation, due to an enhanced interaction between the OMSA support and copper species. ${ }^{44}$ Very weak diffraction peaks are equally observed for Cu/OMA.
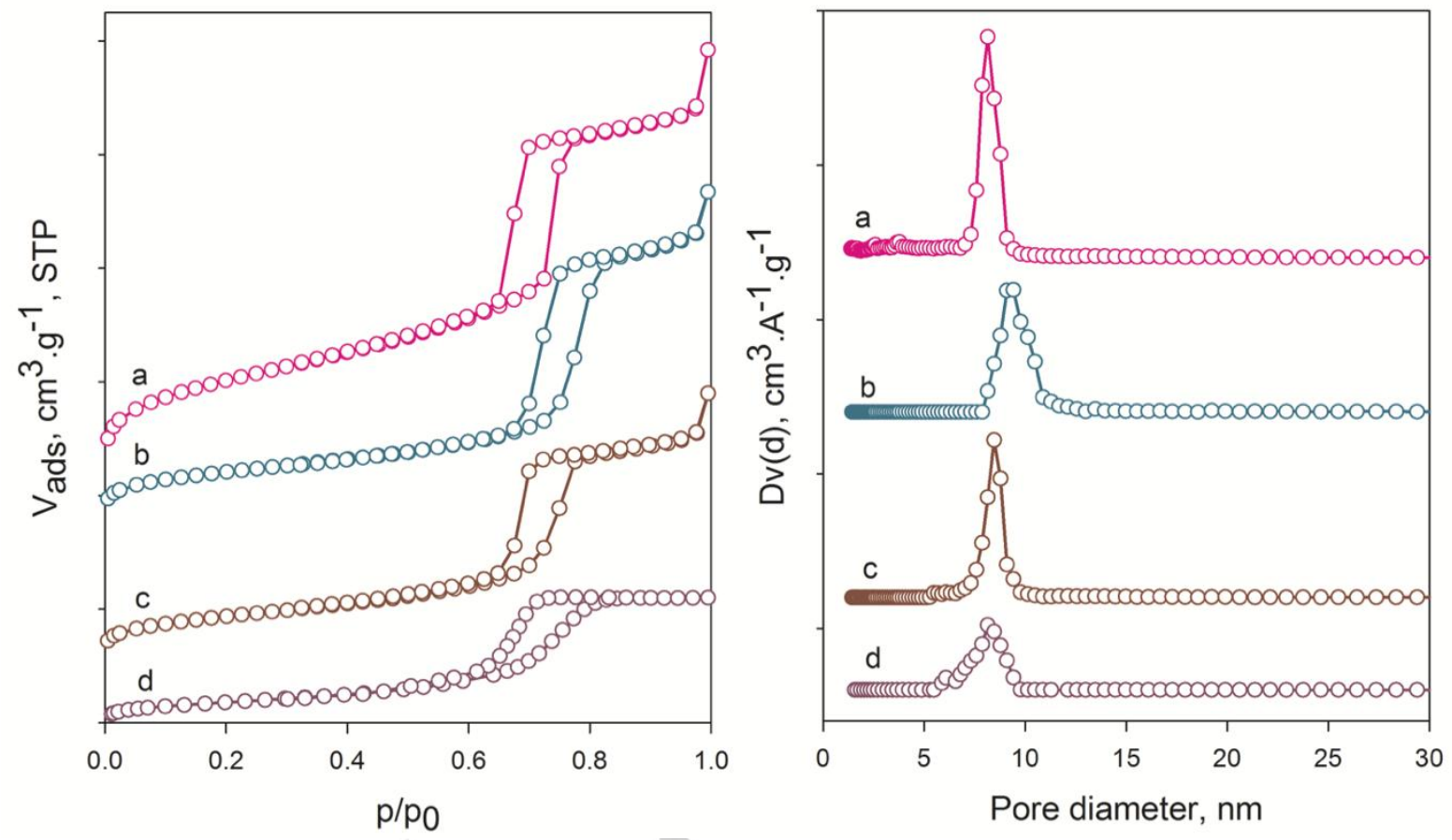

Figure 2. $\mathrm{N}_{2}$ physisorption isotherms (left) and NL-DFT pore size distribution (right) for Cu/OMS (a), Cu/OMSA10 (b), Cu/OMSA20 (c), and Cu/OMA (d)

Textural properties of the supports and of copper-loaded materials were investigated by $\mathrm{N}_{2}$ physisorption at $-196{ }^{\circ} \mathrm{C}$. Figure 2 shows the isotherms and pore size distributions for copper catalysts (characteristics of the bare supports are shown in ESI, Figure S2), whereas Table 1 summarizes the textural properties of all materials.

For Cu/OMS, sharp adsorption/desorption branches specific to highly-ordered materials are observed (isotherm of type IV with $\mathrm{H} 1$ hysteresis loop ${ }^{45,46}$ ), and lead to a narrow pore size distribution centered at $8.2 \mathrm{~nm}$, characteristic of bare mesostructured SBA-15 (Figure 2a). The decrease of specific surface area and pore volume after metal deposition is explained in part by the mixing of SBA-15 with non-porous $\mathrm{CuO}$, that furthermore is present as bulky particles which do not clog the porosity. This interpretation is confirmed by TEM-EDXS analysis (ESI, Figure S3, showing large aggregates of extraporous $\mathrm{CuO}$ particles). A very low copper content is measured in the silica grains (< 0.5 wt. \% by EDXS).

The hysteresis loops of the two Cu/OMSA materials are also well defined. Compared with Cu/OMS, OMSA-derived samples show a decreased specific surface area and pore volume, but - worthy of emphasis - even at high loadings of alumina, the narrow pore size distribution (centered at 9.1 and $8.4 \mathrm{~nm}$ for $\mathrm{Cu} / \mathrm{OMSA} 10$ and Cu/OMSA20, respectively) is maintained (Table 1, Figure $2 \mathrm{c}$ and $\mathrm{d}$ ).

On the other hand, Cu/OMA displays a physisorption isotherm of type IV with a hysteresis loop of type $\mathrm{H} 2$, indicating an ordered mesoporous material, though less structured than OMS. ${ }^{47}$ Surface area and pore volume were 

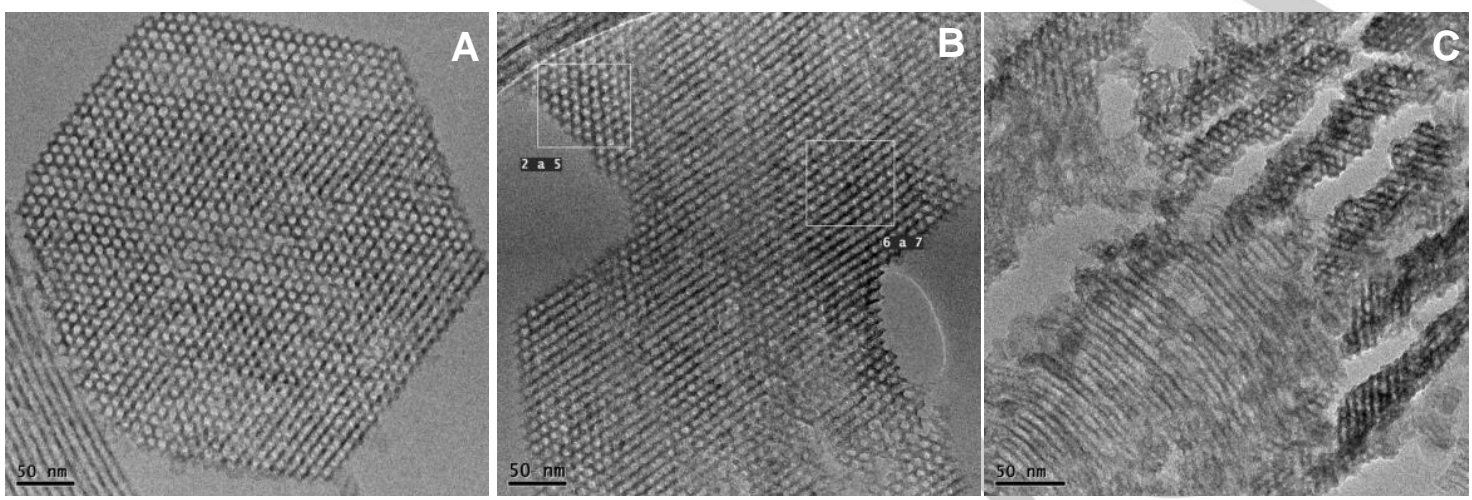

Figure 3. TEM images for calcined materials: (A) Cu/OMSA10, (B) Cu/OMSA20, and (C) Cu/OMA.

TEM images acquired for copper-containing OMSA and OMA materials are displayed in Figure 3. The TEM micrographs for the OMSA samples (images $A$ and $B$ ) confirm an ordering of the mesoporous structure typical of SBA-15 systems. The local structure of the Cu/OMSA solids thus appears to be in excellent agreement with data extracted from nitrogen physisorption and low-angle XRD. No $\mathrm{Al}_{2} \mathrm{O}_{3}$ aggregates are seen blocking the pores of OMSA10 and OMSA20. EDX measurements carried out on the grains (typical spectra are shown in ESI, Figures S4 and S5) are in agreement with the nominal Si/Al atomic ratios ( $\mathrm{Si} / \mathrm{Al}=7-9$ and 3.1-3.5, respectively), indicating that, as formerly demonstrated for these compositions, ${ }^{43}$ aluminium heteroatoms are incorporated within the AI-SBA15 mesostructured supports. The OMA-derived sample also displays ordered hexagonal arrays of mesopores, confirming the retention of the mesostructure after copper deposition by melt infiltration.

As shown in ESI, Figure S4, a few bulky CuO crystallites were identified in the TEM images of $\mathrm{Cu} / \mathrm{OMSA} 10$, but overall the content of copper evaluated by EDX in the mesostructured zones was consistent with the nominal $\mathrm{Cu}$ loading. This is in line with the low amount of $\mathrm{CuO}$ present as large particles detected by high-angle XRD. No extraporous $\mathrm{CuO}$ aggregates could be observed by TEM in the case of Cu/OMSA20 and Cu/OMA. For the sake of comparison, Figure S5 in ESI presents more TEM images of calcined Cu/OMSA20.

These results demonstrate that the OMSA20 support containing $20 \quad$ wt $\% \quad \mathrm{Al}_{2} \mathrm{O}_{3}$ combines the textural characteristics of OMS and a dispersion ability for $\mathrm{CuO}$ similar to that of the OMA support, while benefitting from a high stability when exposed to aqueous solutions. Results published so far in the literature, and related to other methods of $\mathrm{Cu}$ introduction, have evidenced contrasting trends. While Orellana Rico et al. mentioned an improvement of copper dispersion on Al-containing SBA-15 silica, ${ }^{49}$ Yin et al. reported that an excessive amount of aluminium $(\mathrm{Si} / \mathrm{Al}=5)$ had a negative effect on the copper dispersion when the catalysts were prepared by depositionprecipitation (copper loading of $20 \mathrm{wt} \%$ ). ${ }^{44}$ Nilsen et al. prepared Cu-Al-MCM41 materials by direct synthesis, with 10.7 wt. \% of copper, and a Si/Al ratio of 20 . They observed that $\mathrm{CuO}$ was present as an extra-porous phase despite the high amount of aluminium incorporated into the solid. ${ }^{50}$

\section{Nature and reducibility of the copper phases}

The chemical and electronic characteristics of the copper phases were investigated by XPS for the Cu/OMSA20 sample, after calcination and after reduction at $500^{\circ} \mathrm{C}$. Cu $2 p$ core level spectra are presented in Figure 4. The calcined sample shows the $\mathrm{Cu} 2 \mathrm{p}_{3 / 2}$ and $2 \mathrm{p}_{1 / 2}$ doublet peaks centered at 933.3 and $952.8 \mathrm{eV}$, respectively, with a spin-orbit splitting (SOS) of 19.6 $\mathrm{eV}$. The absence of a peak located at $932.4 \mathrm{eV}$ indicates that there are no bulk-like copper oxide NPs. ${ }^{51}$ A shoulder at 935.4 $\mathrm{eV}$ on the $2 \mathrm{p}_{3 / 2}$ peak suggests a charge transfer from metal ions toward the support, and the formation of species in which copper is in strong interaction with the support. ${ }^{44,52-54} \mathrm{~A}$ small satellite peak, arising from the $3 d-4 s$ transition during the relaxation process ${ }^{55}$ is observed at $944.5 \mathrm{eV},(11.2 \mathrm{eV}$ from the main peak).

XPS thus indicates the existence of $\mathrm{Cu}^{2+}$ species in two different chemical environments: the contribution at $\mathrm{BE}=933.3 \mathrm{eV}$ is attributed to highly dispersed $\mathrm{CuO}$, while the value at $\mathrm{BE}=935.4$ $\mathrm{eV}$ is assigned to copper in a $\mathrm{CuAl}_{2} \mathrm{O}_{4}$ spinel phase. The low ratio between the intensities of the main peak and satellite peak $\left(I_{s a t} / I_{p p}=0.07\right)$ may also be assigned to highly dispersed $\mathrm{CuO}_{x}$ species in octahedral coordination ${ }^{56}$ (in contrast with a value of 0.55 for bulk $\mathrm{CuO}^{52,53}$ ). A correlation of this low $I_{s a t} / I_{p p}$ value with the existence of $\mathrm{Cu}^{+}$species would not be relevant because no signal specific to $\mathrm{Cu}^{+} / \mathrm{Cu}^{0}$ species at $\sim 932 \mathrm{eV}$ can be detected for the calcined sample. ${ }^{57-59}$

After reduction at $500{ }^{\circ} \mathrm{C}$, the binding energy is shifted to a lower value as expected for metallic $\mathrm{Cu}(932.8 \mathrm{eV})$ while 
the satellite peak disappears, revealing that all the copper species are in a reduced form. ${ }^{44}$

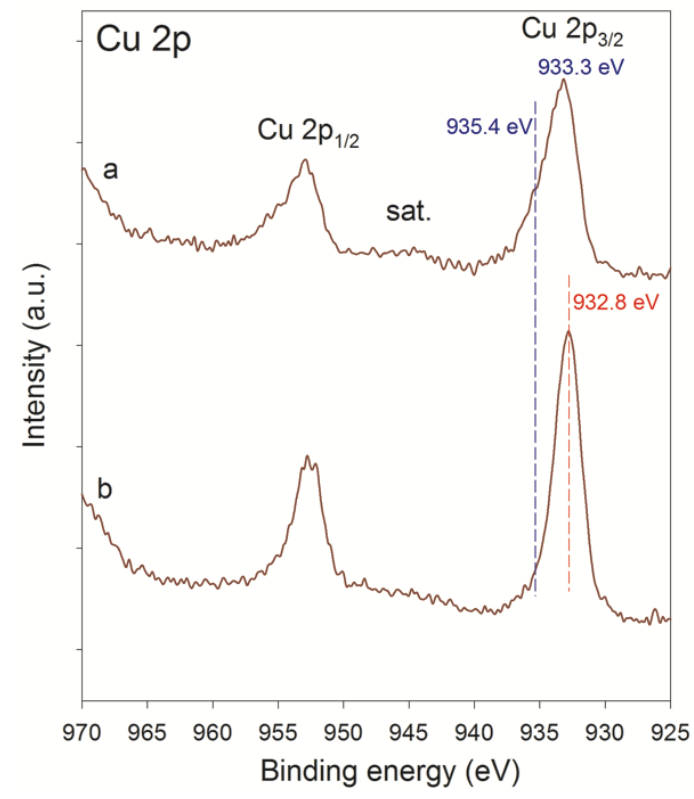

Figure 4. Cu $2 p$ XPS spectra of calcined (a) and reduced (b) Cu/OMSA20

Thermo-programmed reduction (TPR) was used to determine the reducibility of the copper species and confirm their characteristics in terms of dispersion and interaction with the support (Figure 5). The TPR profile for $\mathrm{Cu} / \mathrm{OMS}$ exhibited a single hydrogen consumption peak with a maximum at $286^{\circ} \mathrm{C}$, corresponding to the reduction of bulk $\mathrm{CuO}^{60}$ This interpretation is in line with the XRD and TEM results obtained for this material (large $\mathrm{CuO}$ particles outside the SBA-15 porosity).

When the aluminum loading increases in the sample, the reduction profile becomes more complex and reduction temperatures shift to higher values. These changes can be related to the $\mathrm{CuO}$ particle size ${ }^{61}$ or to interactions with the $\mathrm{Al}_{2} \mathrm{O}_{3}$ - functionalized support surface. Due to the progressive evolution of the chemical nature of the support, the reduction behavior of copper species supported on $\gamma$-alumina was thus considered as a reference, with copper aluminate reducing at the highest temperature. ${ }^{62}$ The most complex profile belongs to $\mathrm{Cu} / \mathrm{OMSA} 10$, with multiple reduction steps. Three maxima of reduction could be defined, at $220^{\circ} \mathrm{C}, 308^{\circ} \mathrm{C}$ and $410{ }^{\circ} \mathrm{C}$, respectively assigned to the small amount of external bulk-like oxide particles, highly dispersed copper oxide particles in the porosity, and copper species in strong interaction with the surface $\left(\mathrm{CuAl}_{2} \mathrm{O}_{4}\right) \cdot{ }^{60,61,63-66}$ The profile of Cu/OMSA20 resembles to that of $\mathrm{Cu} / \mathrm{OMA}$ sample, suggesting similar characteristics of $\mathrm{Cu}$ species in the two materials. The main reduction peaks are observed at 310 and $390^{\circ} \mathrm{C}(\mathrm{Cu} / \mathrm{OMSA} 20)$, and 340 and $410{ }^{\circ} \mathrm{C}$ $(\mathrm{Cu} / \mathrm{OMA})$. Most copper is thus in strong interaction with the support, as dispersed $\mathrm{CuO}$ or copper aluminate, expected to predominate at low $\mathrm{Cu}$ loading and for calcination temperatures up to $500{ }^{\circ} \mathrm{C}$. ${ }^{65}$ For Cu/OMSA20, a shoulder located at $220{ }^{\circ} \mathrm{C}$ could originate from the reduction of residual $\mathrm{CuO}$ in weak interaction with the support.

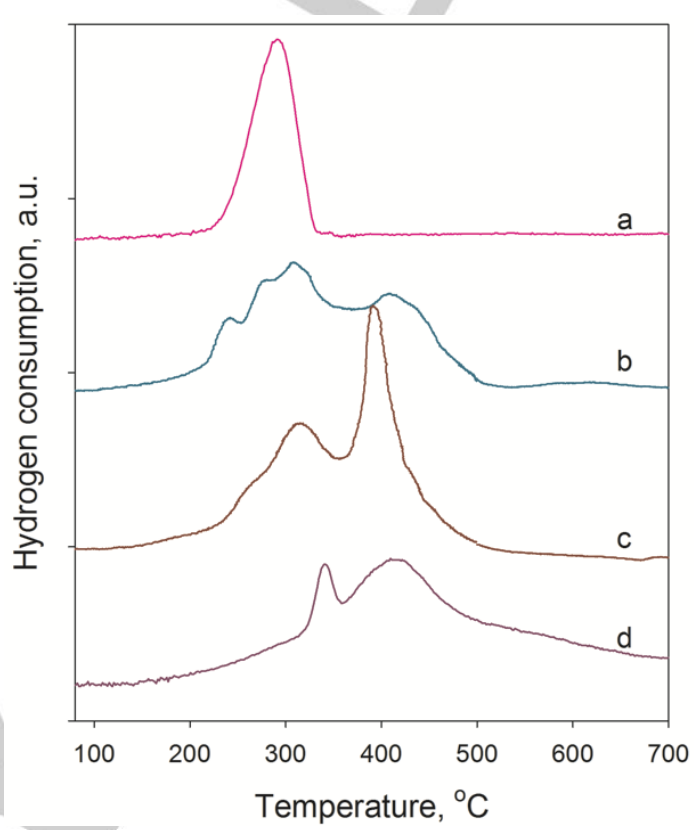

Figure 5. TPR profiles for Cu/OMS (a), Cu/OMSA10 (b), Cu/OMSA20 (c), and $\mathrm{Cu} / \mathrm{OMA}(\mathrm{d})$

\section{Dispersion of copper active phase}

The dispersion of metallic copper after reduction at $500^{\circ} \mathrm{C}$ was determined by $\mathrm{N}_{2} \mathrm{O}$ chemisorption. ${ }^{66-69}$ According to TPR data, this temperature is consistent with the reducibility of the copper species and will be chosen for reduction of copper prior to the catalytic reaction. Results are expressed as copper dispersion $\left(\mathrm{D}_{\mathrm{Cu}}\right)$, average particle size $\left(\mathrm{d}_{\mathrm{Cu}}\right)$, and metallic copper accessible surface area $\left(\mathrm{S}_{\mathrm{Cu}}\right)$ (Table 2$)$.

The dispersion of copper and the associated metallic surface area both increase as the aluminum content in the support increases. In particular, the values found for Cu/OMSA20 are very similar to those obtained for Cu/OMA, confirming that on OMSA20, copper particles present characteristics close to those on mesoporous alumina.

Table 2. $\mathrm{N}_{2} \mathrm{O}$ chemisorption data for the copper-based catalysts

\begin{tabular}{lcccc} 
Sample & $\mathrm{D}_{\mathrm{Cu}}{ }^{[\mathrm{a}]}, \%$ & $\mathrm{~d}_{\mathrm{Cu}}{ }^{[\mathrm{b}]}, \mathrm{nm}$ & $\mathrm{S}_{\mathrm{Cu}}{ }^{[\mathrm{cc}]}, \mathrm{m}^{2}{ }_{\mathrm{Cu}} \mathrm{cat}^{-1}$ & $\mathrm{~S}_{\mathrm{Cu}^{[\mathrm{c}]}, \mathrm{m}^{2}{ }_{\mathrm{Cu}} \mathrm{Cu}^{-1}}$ \\
\hline Cu/OMS & 4.6 & 21.6 & 1.4 & 31.1 \\
Cu/OMSA10 & 18.8 & 5.3 & 5.6 & 127.2 \\
Cu/OMSA20 & 25.6 & 3.9 & 7.6 & 173.2 \\
Cu/OMA & 28.0 & 3.6 & 9.3 & 189.4 \\
\hline
\end{tabular}


[a] Cu dispersion; [b] Average particle size of Cu particles; [c] Accessible surface of metallic $\mathrm{Cu}$

\section{Catalytic properties}

The catalytic properties of the above-discussed copperbased solids were evaluated in the liquid phase hydrogenation of cinnamaldehyde (CNA). As shown in Scheme 1, this process involves parallel and consecutive reactions, with the possible formation of partially hydrogenated molecules (hydrocinnamaldehyde - HCNA; cinnamyl alcohol - CNOL) and of a fully hydrogenated product (hydrocinnamyl alcohol - HCNOL).

$\mathrm{Cu} / \mathrm{OMS}$ shows a very low activity ( 9 \%) after $6 \mathrm{~h}$ of reaction (Figure $6 \mathrm{~A}$ ). It is related to the poor dispersion of copper and consequently to a low exposed active surface. ${ }^{26,34}$ Activity increases with the increase of $\mathrm{Cu}$ exposed surface area (Table 2), and thus with the aluminum content in the support. Cu/OMSA10 and Cu/OMSA20 leads to CNA conversions of $\sim 48$ and $~ 80 \%$ after $6 \mathrm{~h}$ of reaction, respectively. Interestingly, the activity obtained for the $\mathrm{Cu} / \mathrm{OMA}$ catalyst is essentially similar to that of $\mathrm{Cu} / \mathrm{OMSA} 20$, despite the fact that $\mathrm{Cu} / \mathrm{OMA}$ presents a slightly higher Cu NPs dispersion.

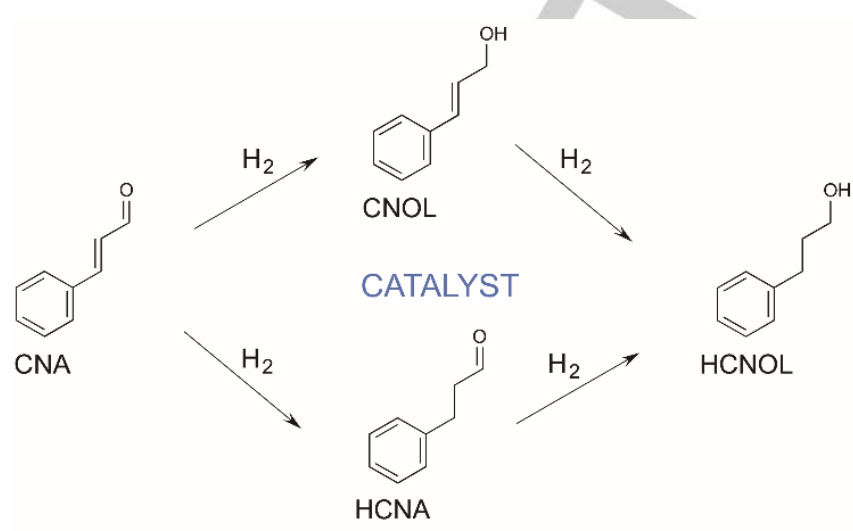

Scheme 1. Reaction pathways for the hydrogenation of cinnamaldehyde
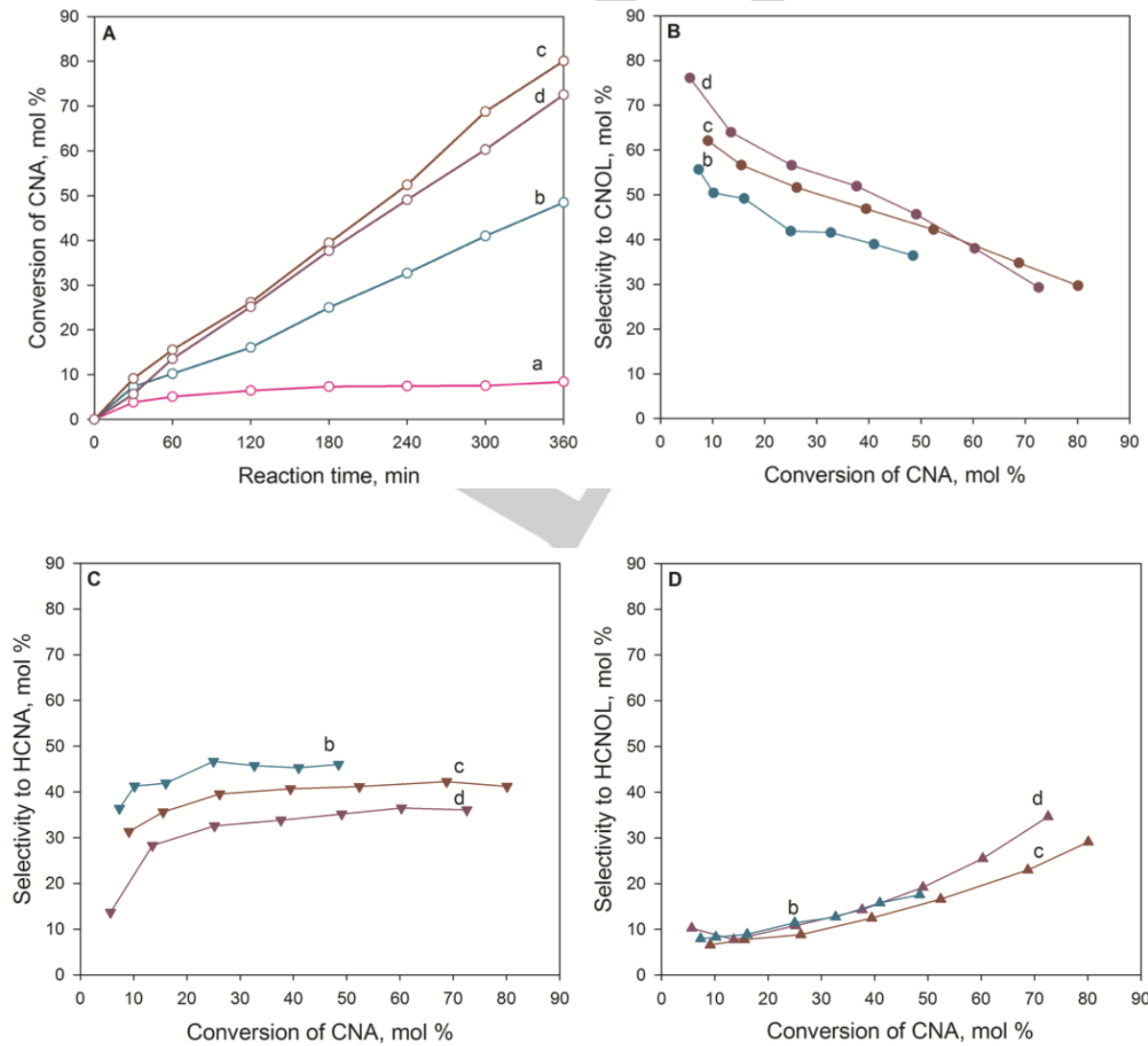

Figure 6. Catalytic activity (A) and selectivity to CNOL (B), HCNA (C) and HCNOL (D) for Cu/OMS (a), Cu/OMSA10 (b), Cu/OMSA20 (c), and Cu/OMA (d) Reaction conditions: $\mathrm{T}_{\text {reduction }}=500^{\circ} \mathrm{C} ; \mathrm{T}_{\text {reaction }}=110^{\circ} \mathrm{C} ; 250 \mathrm{mg}$ of catalyst; $1 \mathrm{~mL}$ of $\mathrm{CNA}, 40 \mathrm{~mL}$ of iso-propanol; $\mathrm{P}_{\mathrm{H} 2}=10 \mathrm{bar}$; stirring rate $=750 \mathrm{rpm}$.

At maximum conversion ( $9 \%$ ), the OMS-supported catalyst exhibited selectivities to CNOL, HCNA and HCNOL of 44 ,
49 and $7 \%$, respectively. Figures 6 B-D display the selectivities to CNOL, HCNA and HCNOL, respectively, as 
a function of conversion for the OMSA and OMA-supported systems. The dominant product at low conversion is that resulting from the hydrogenation of the $\mathrm{C}=\mathrm{O}$ bond, namely CNOL (selectivity of $57 \%$ for Cu/OMSA10, 62\% for Cu/OMSA20, $78 \%$ for Cu/OMA). Selectivities to CNOL are however observed to decrease with increasing conversion (41, 47 and $51 \%$ measured for Cu/OMSA10, Cu/OMSA20 and $\mathrm{Cu} / \mathrm{OMA}$, respectively, at $\mathrm{X}_{\mathrm{CNA}}=40 \%$ ), while the selectivity to HCNA, resulting from the hydrogenation of the $\mathrm{C}=\mathrm{C}$ bond, increases. Once conversion has reached $40 \%$, the selectivity to $\mathrm{HCNOL}$, the total hydrogenation product, increases while the $\mathrm{CNOL}$ selectivity further decreases, down to $\sim 30 \%$ at $\mathrm{X}_{\mathrm{CNA}} \sim 80 \%$. At any conversion below $40 \%$, the contribution of HCNOL to the sum of the products lies in the range $8-20 \%$ with no influence of the amount of aluminium, while the selectivity to CNOL increases and that to HCNA decreases when more aluminum is incorporated.

The production of CNOL is usually related to the existence of large metal particles. The OMS-supported catalyst (large Cu particles, $31.5 \mathrm{~nm}$ ) exhibits similar selectivites to CNOL and HCNA, at a low level of conversion (9\%). Chambers et al. reported that $18 \mathrm{~nm} \mathrm{Cu}$ particles enhance CNOL selectivity. ${ }^{33}$ Rudolf et al. showed that the size of small nanoparticles of metallic copper $(2.3-6 \mathrm{~nm})$ supported on a mesoporous silica did not influence the adsorption of CAN, and that a low selectivity to CNOL $(<5 \%$ for a conversion of $40 \%$ ) was obtained for all catalysts. ${ }^{28}$

In our case, it is the presence of small $\mathrm{Cu}$ particles and of an alumina-rich support surface that both ensures a high activity and favours the hydrogenation of the $\mathrm{C}=\mathrm{O}$ bond with respect to that of the $\mathrm{C}=\mathrm{C}$ bond (selectivity to $\mathrm{CNOL}$ between 60 and $80 \%$ at conversion $<10 \%$, between 50 and $60 \%$ at conversion $=30 \%$ ). Gutierrez et al. reported selectivities to $\mathrm{CNOL}$ on alumina-supported $\mathrm{Cu}$ catalysts very close to the values obtained here on Cu/OMA and Cu/OMSA20 (51\% at a conversion of $30 \%)$, but on larger copper particles $(6-19 \mathrm{~nm}$, compared to the values calculated here, $3-4 \mathrm{~nm}){ }^{37}$ The TOF value calculated from our results on Cu/OMSA20 $\left(610^{-3} \mathrm{~s}^{-1}\right.$ at $\left.110^{\circ} \mathrm{C}\right)$ compares well with the TOF values given for their most active $\mathrm{Cu}$ catalysts $\left(5-710^{-3} \mathrm{~s}^{-1}\right.$ at $100^{\circ} \mathrm{C}$ in isopropanol). Selectivities to CNOL mentioned by Marchi et al. ${ }^{34}$ on ternary or quaternary $\mathrm{Al}$-containing catalysts, on which $\mathrm{Cu}$ was highly dispersed, are also similar to ours (selectivity to $\mathrm{CNOL}=$ $47-53 \%$ at a conversion of $30 \%, 36-38 \%$ at a conversion of $60 \%)$. Surface Lewis acid sites brought by the introduction of aluminum species and in the close vicinity of the metallic sites are most likely involved in the adsorption of CNA molecules via polar $\mathrm{C}=\mathrm{O}$ bond, ${ }^{41}$ as also observed for other systems, like Rh supported on oxides such as $\mathrm{TiO}_{\mathrm{x}}, \mathrm{VO}_{\mathrm{x}}$, $\mathrm{ZrO}_{x}$ etc. ${ }^{70}$, $\mathrm{Pt}$ on supports manifesting SMSI effects $\left(\mathrm{TiO}_{2}\right),{ }^{71}$ or bimetallic catalysts containing one of the metallic elements in a cationic state. ${ }^{72}$

\section{Conclusions}

Al-SBA-15 mesoporous silica-alumina materials with high Al content were used as supports for copper NPs. Al was introduced during the synthesis of the SBA-15 support following a two-step $\mathrm{pH}$-adjustment method, and $\mathrm{Cu}$ was introduced by a standard incipient wetness impregnation procedure using an aqueous solution of copper nitrate. Reference samples were prepared by using ordered mesoporous silica and alumina supports. The results evidenced that a significant gain in copper NPs dispersion was achieved over the aluminum containing supports, with a dispersion enhancement from $<5 \%$ (when copper is dispersed over silica support) up to $>25 \%$ (when copper is dispersed over an aluminum-rich support). It has been shown that a water-stable SBA- 15 support containing 20 wt $\%$ of alumina displays a dispersing effect similar to a pure mesoporous alumina support, on which impregnation with aqueous solutions cannot be carried out owing to a lack of stability when exposed to water. The stabilization of copper over aluminum-rich supports is suggested to stem from $\mathrm{CuAl}_{2} \mathrm{O}_{4}$ species generated during thermal treatment.

In line with the high exposed metallic area, copper-based catalysts on aluminum-rich supports (20 wt\% alumina and pure alumina) showed a high activity in the hydrogenation of cinnamaldehyde in liquid phase. These catalysts exhibited a high selectivity to cinnamyl alcohol, showing a preferential hydrogenation of the $\mathrm{C}=\mathrm{O}$ bond up to a conversion of around $50 \%$. Hence, our results show that the introduction of aluminum into the SBA-15 silica has multiple consequences: stabilization of copper as highly dispersed NPs on the internal surface of the mesopores, and improvement of both the activity and selectivity of the copper catalysts by promoting dispersion and changing the adsorption mode of CNA molecules onto the catalyst surface.

\section{Experimental Section}

\section{Materials}

All chemicals required to prepare the supports and the catalysts were used as purchased: tetraethylorthosilicate $\left(\mathrm{Si}\left(\mathrm{OC}_{2} \mathrm{H}_{5}\right)_{4}\right.$, TEOS, 98\%, Sigma-Aldrich), nonionic triblock copolymer Pluronic P123 (poly(ethyleneoxide)-block-poly-(propyleneoxide)-block-

poly(ethyleneoxide)-block, $\mathrm{EO}_{20} \mathrm{PO}_{70} \mathrm{EO}_{20}$, molecular weight = 5800 , BASF Corp.), distilled water, hydrochloric acid $(\mathrm{HCl}, 37 \%$, Sigma-Aldrich), nitric acid $\left(\mathrm{HNO}_{3}, 67 \%\right.$, Sigma-Aldrich), aluminum iso-propoxide $\left(\mathrm{C}_{9} \mathrm{H}_{21} \mathrm{AlO}_{3}, 98 \%\right.$, Sigma-Aldrich), ethanol $\left(\mathrm{C}_{2} \mathrm{H}_{6} \mathrm{O}\right.$, $100 \%$, Sigma-Aldrich), aluminum nitrate $\left(\mathrm{Al}\left(\mathrm{NO}_{3}\right)_{2} \cdot 9 \mathrm{H}_{2} \mathrm{O}, 98.5 \%\right.$, Sigma-Aldrich), ammonium hydroxide solution (28\% in water, Fluka), and copper nitrate $\left(\mathrm{Cu}\left(\mathrm{NO}_{3}\right)_{2} \cdot 3 \mathrm{H}_{2} \mathrm{O}, 98 \%\right.$, Sigma-Aldrich). For the hydrogenation of trans-cinnamaldehyde, the chemicals were also used as purchased: trans-cinnamaldehyde $\left(\mathrm{C}_{6} \mathrm{H}_{5} \mathrm{C}_{3} \mathrm{H}_{3} \mathrm{O}\right.$, $98 \%$, Merck) as reagent and iso-propanol $\left(\mathrm{C}_{3} \mathrm{H}_{8} \mathrm{O}, 99.9 \%\right.$, SigmaAldrich) as solvent.

\section{Synthesis of samples \\ Supports}

OMS (ordered mesoporous silica) support was synthesized according to the procedure proposed by Zhao et al. ${ }^{73} 4 \mathrm{~g}$ of Pluronic $\mathrm{P} 123$ was dissolved in a $1.6 \mathrm{M}$ solution of $\mathrm{HCl}$ at $40{ }^{\circ} \mathrm{C}$. The 
appropriate amount of TEOS ( $8.5 \mathrm{~g})$ was then added dropwise to the above solution, which was subjected to magnetic stirring for 24 h. The resulting gel was submitted to hydrothermal treatment for 48 $\mathrm{h}$ at $100{ }^{\circ} \mathrm{C}$. After recovering by filtration, washing, and drying, the structure directing agent was removed from the pores by calcination under stagnant air at $550{ }^{\circ} \mathrm{C}$ for $6 \mathrm{~h}$ (in a muffle furnace, using a heating ramp of $1.5^{\circ} \mathrm{C} \mathrm{min}{ }^{-1}$ ).

OMSA (ordered mesoporous silica-alumina) supports were prepared by a two-step $\mathrm{pH}$-adjustment method, according to a procedure previously established. ${ }^{43}$ The synthesis was carried out as follows: (step 1) was performed as for OMS support, with aluminum source added after $4 \mathrm{~h}$ of stirring, during the aging step of $24 \mathrm{~h}$. The amounts of $\mathrm{Al}\left(\mathrm{NO}_{3}\right)_{3} \cdot 9 \mathrm{H}_{2} \mathrm{O}$ were calculated to obtain an alumina content of 10 and $20 \mathrm{wt} . \%$, in the final materials. The aged gel was subjected to a first hydrothermal treatment at $100{ }^{\circ} \mathrm{C}$ for 72 $\mathrm{h}$; for (step 2), the suspension resulting from (step 1) was cooled down to ambient temperature and then, the $\mathrm{pH}$ value of the mother liquor was adjusted to 7.5 by using a $4 \mathrm{M}$ ammonia solution. The $\mathrm{pH}$ was continuously monitored with a calibrated $\mathrm{pH}$-meter. After $\mathrm{pH}$ adjustment, the mixture was subjected to a second hydrothermal treatment at $100{ }^{\circ} \mathrm{C}$ for $48 \mathrm{~h}$. The final solids were recovered by filtration, washing with distilled water, and drying at $60^{\circ} \mathrm{C}$ for $12 \mathrm{~h}$. The open porous structures of OMSA were obtained by calcination (see OMS preparation section). The calcined aluminosilicate samples were designated as OMSA $X$, where $X$ stands for the aluminum content in the material expressed as wt.\% $\mathrm{Al}_{2} \mathrm{O}_{3}(\mathrm{X}=10$ and 20).

OMA (ordered mesoporous alumina) support was prepared using the EISA method proposed by Yuan et al. ${ }^{74} 1 \mathrm{~g}$ of Pluronic P123 was dissolved at room temperature in $40 \mathrm{~mL}$ of anhydrous ethanol. $3 \mathrm{~mL}$ of $\mathrm{HNO}_{3}(67 \%)$ and $2.04 \mathrm{~g}$ of aluminum iso-propoxide were added into the mixture under vigorous stirring at room temperature for $5 \mathrm{~h}$. Solvent evaporation was performed at $60^{\circ} \mathrm{C}$. When the total evaporation was achieved, the yellow solid was recovered and calcined in stagnant air at $500^{\circ} \mathrm{C}\left(1^{\circ} \mathrm{C} \mathrm{min}{ }^{-1}\right)$.

\section{Catalysts}

Catalysts were denoted by Cu/MS where MS stands for the mesoporous support (MS = OMS, OMSAX). All nominal loadings were 5 wt.\% metallic $\mathrm{Cu}$. Metal oxide-loaded OMS and OMSA samples were prepared by incipient wetness impregnation using aqueous copper nitrate solutions, followed by mild drying $\left(25 \pm 1^{\circ} \mathrm{C}\right.$ under air for 5 days)..$^{25}$ The powders were submitted to calcination under stagnant air at $500^{\circ} \mathrm{C}$ for $6 \mathrm{~h}$ (heating ramp of $1.5^{\circ} \mathrm{C} \mathrm{min}{ }^{-1}$ ) to obtain the oxidic form of $\mathrm{Cu}$. After calcination, the solids were stored under ambient conditions in sealed flasks. Cu/OMA catalyst was prepared by a solvent-free, melt infiltration (MI) procedure. ${ }^{27,75,76}$ This method was chosen because, when contacted with water (the solvent usually used for impregnation), OMA is subjected to a significant loss of pore structure ordering. ${ }^{47}$ The $\mathrm{MI}$ method involved mixing the appropriate amounts of $\mathrm{Cu}\left(\mathrm{NO}_{3}\right)_{2} \cdot 3 \mathrm{H}_{2} \mathrm{O}$ and OMA, followed by grinding for $45 \mathrm{~min}$. The solid mixture was heat-treated at $120^{\circ} \mathrm{C}$ in sealed conditions. The obtained infiltrate was calcined under the same conditions as the other catalysts. It can be noted that MI failed to introduce copper nitrate into the porosity of siliceous SBA-15, resulting in the formation of large metallic particles outside the pores.

\section{Physico-chemical characterization}

Inductively coupled plasma optical emission spectrometry (ICPOES) was performed on a Perkin sequential scanning spectrometer to determine the amount of copper in the catalysts. Before analysis, a known amount of calcined sample was introduced in a diluted HF$\mathrm{HCl}$ solution and then digested under microwave.

Powder X-ray diffraction (XRD) was performed on a Bruker AXS D5005 X-ray diffractometer, using Cu Ka radiation ( $\lambda=1.54184 \AA$ ). For high-angle analysis, the data were collected in the $2 \theta$ range 10 $-80^{\circ}$ with a step of $0.05^{\circ}$ (step time of $8 \mathrm{~s}$ ). Phase identification was made by comparison with the ICDD database. The average crystallite size of $\mathrm{CuO}$ was calculated according to the Scherrer equation for the most intense diffraction lines at 35.5 and $38.7^{\circ}$.

Nitrogen physisorption was carried out on an Autosorb MP-1 automated gas sorption system from Quantachrome Instruments. The textural data were calculated from the corresponding isotherms using conventional algorithms (B.E.T. for surface area measurement, and NL-DFT for pore size distribution).

$X$-ray photoelectron spectroscopy (XPS) was performed on an ESCALAB 250 (Thermo Electron, Thermo Fisher Scientific, WI) photoelectron spectrometer equipped with a monochromatic Al-Ka source (1486.6 eV, powered at $20 \mathrm{~mA}$ and $10 \mathrm{kV})$. Binding energies were determined relatively to the Si $2 p$ XPS peak set at $103.2 \mathrm{eV}$. Transmission electronic microscopy (TEM) coupled with energydispersive X-ray spectroscopy (EDXS) was used to characterize the pore structure of the supports and the distribution of $\mathrm{Cu}$. The micrographs were obtained on a JEOL 2100 instrument (operated at $200 \mathrm{kV}$ with $\mathrm{a} \mathrm{LaB}_{6}$ source and equipped with a Gatan Ultra scan camera). EDXS was carried out with a Hypernine (Premium) detector (active area: $30 \mathrm{~mm}^{2}$ ) using the software SM-JED 2300T for data acquisition and treatment. Before analysis, the sample was included in a resin and crosscuts of $\sim 100 \mathrm{~nm}$ were realized by ultramicrotomy.

Temperature programmed reduction (TPR) and $\mathrm{N}_{2} \mathrm{O}$ chemisorption were performed on a Chembet Pulsar TPR/TPD instrument from Quantachrome. About $30 \mathrm{mg}$ of calcined samples were inserted in a U-shape microreactor. Before each TPR run, the catalyst was activated at $500{ }^{\circ} \mathrm{C}$ for $1 \mathrm{~h}$ under a flow of simulated air $(40 \mathrm{~mL}$ min $\left.{ }^{1}\right)$. After cooling down to $50{ }^{\circ} \mathrm{C}$, the $\mathrm{H}_{2}$ containing flow was stabilized ( $40 \mathrm{~mL} \mathrm{~min}^{-1}, 5$ vol. $\% \mathrm{H}_{2}$ in $\mathrm{Ar}$ ) and the TPR was performed from 50 to $700{ }^{\circ} \mathrm{C}$, with a temperature ramp of $5{ }^{\circ} \mathrm{C} \mathrm{min}{ }^{-1}$. The dispersion of metallic copper $\left(\mathrm{D}_{\mathrm{Cu}}\right)$, average copper particle size $\left(\mathrm{d}_{\mathrm{Cu}}\right)$ and active surface area $\left(\mathrm{S}_{\mathrm{Cu}}\right)$ were determined using nitrous oxide chemisorption with the Quantachrome device. ${ }^{58-60} 30 \mathrm{mg}$ of samples were introduced in the microreactor. The first reduction was carried out under the same conditions as used for TPR, up to $500{ }^{\circ} \mathrm{C}$. The gas was switched to Ar. The reactor was cooled down to $50{ }^{\circ} \mathrm{C}$, kept at this temperature for $30 \mathrm{~min}$, and then the gas was switched to $\mathrm{N}_{2} \mathrm{O}\left(40 \mathrm{~mL} \mathrm{~min}{ }^{-1}\right)$ for $30 \mathrm{~min}$ in order to oxidize the zero-valent $\mathrm{Cu}$ surface atoms to $\mathrm{Cu}_{2} \mathrm{O}$. The sample was again flushed with pure Ar for $30 \mathrm{~min}$, and then a second TPR run was performed.

\section{Catalytic testing}

Prior to the catalytic tests, the calcined materials were crushed and sieved to select a granulometric fraction smaller than $0.126 \mathrm{~mm}$. Catalysts were reduced under hydrogen flow $\left(1 \mathrm{~L} \mathrm{~h}^{-1}\right)$ at $500{ }^{\circ} \mathrm{C}$ for 
$10 \mathrm{~h}$ (heating rate $6{ }^{\circ} \mathrm{C} \mathrm{min}^{-1}$ ) in order to obtain the metallic catalysts. Cinnamaldehyde hydrogenation was performed in liquid phase in a 4593 Parr reactor. The experimental conditions were: reaction temperature $110^{\circ} \mathrm{C}, 1 \mathrm{~mL}$ of trans-cinnamaldehyde, $40 \mathrm{~mL}$ of iso-propanol, $250 \mathrm{mg}$ of catalyst, $\mathrm{H}_{2}$ pressure $10 \mathrm{bar}$, stirring rate of $750 \mathrm{rpm}$. Aliquots of reaction mixture were periodically taken for analysis. Analysis was performed by GC (HP 5890 equipped with a DB-5 capillary column and a FID detector). Identification of the reactants and products was achieved from the retention times of pure compounds, and occasionally by GC-MS (Agilent $6890 \mathrm{~N}$ system equipped with an Agilent 5973 MSD detector and a DB-5ms column). For the quantitative analyses, the FID response factors for each compound were taken into consideration.

\section{Acknowledgements}

This work was supported by three grants of the Romanian National Authority for Scientific Research, CNCSUEFISCDI (Projects PN-II-RU-TE-2012-3-0403, PN-II-IDPCE-2011-3-0868, and PN-II-CT-RO-FR-2012-1-0052 Bilateral program Hubert Curien-Brancusi). C Ciotonea (784016L) and I. Mazilu (812773E) acknowledge the Ministère des affaires étrangères et du développement international for Eiffel Excellence fellowships. C. Ciotonea acknowledges the Fondation de l'Université de Poitiers for financial support. C. Ciotonea, S. Royer and E. Marceau acknowledge Chevreul Institute (FR 2638), Ministère de l'Enseignement Supérieur et de la Recherche, Région Nord - Pas de Calais and FEDER for funding.

Keywords: copper nanoparticles • mesoporous materials • aluminium doping $\bullet$ hydrogenation $\bullet$ cinnamaldehyde

[1] M. B. Gawande, A. Goswami, F.-X. Felpin, T. Asefa, X. Huang, R. Silva, X. Zou, R. Zboril, R. S. Varma, Chem. Rev., 2016, 116, 3722-3811.

[2] L.-F. Chen, P.-J. Guo, L.-J. Zhu, M.-H. Qiao, W. Shen, H.-L. Xu, K.-N. Fan, Appl. Catal. A, 2009, 356, 129-136.

[3] J. S. Yang, W. Y. Jung, G.-D. Lee, S. S. Park, S.-S. Hong, Top. Catal., 2010, 53, 543-549.

[4] A. Patel, T. E. Rufford, V. Rudolph, Z. Zhu, Catal. Today, 2011, 166, 188193.

[5] A. Patel, P. Shukla, T. Rufford, S. Wang, J. Chen, V. Rudolph, Z. Zhu, Appl Catal. A, 2011, 409- 410, 55- 65.

[6] C. K. P. Neeli, A. Narani, R. K. Marella, K. S. R. Rao, D. R. Burri, Catal. Commun., 2013, 39, 5-9.

[7] A. Szegedi, M. Popova, K. Lázár, S. Klébert, E. Drotár, Microporous Mesoporous Mater., 2013, 177, 97-104.

[8] D. Vargas-Hernández, J. M. Rubio-Caballero, J. Santamaría-González, R. Moreno-Tost, J.M. Mérida-Robles, M.A. Pérez-Cruz, A. Jiménez-López, R. Hernández-Huesca, J. Mol. Catal. A-Chem., 2014, 383-384, 106-113.

[9] X. Duan, W. Liu, L. Yue, W. Fu, M. N. Ha, J. Li, G. Lu, Dalton Trans., 2015, 44, 17381-17388.

[10] S. Srivastava, N. Solanki, P. Mohanty, K. A. Shah, J. K. Parikh, A. K. Dalai, Catal. Lett., 2015, 145, 816-823.

[11] C.-H. Liu, N.-C. Lai, J.-F. Lee, C.-S. Chen, C.-M. Yang, J. Catal., 2014, $316,231-239$

[12] T. Tsoncheva, I. Genova, M. Stoyanova, M.-M. Pohl, R. Nickolov, M. Dimitrov, E. Sarcadi-Priboczki, M. Mihaylov, D. Kovacheva, K. Hadjiivanov, Appl. Catal. B., 2014, 147, 684-697.
[13] C.-H. Tu, A.-Q. Wang, M.-Y. Zheng, X.-D. Wang, T. Zhang, Appl. Catal. A 2006, 297, 40-47.

[14] X. Zheng, H. Lin, J. Zheng, H. Ariga, K. Asakura, Y. Yuan, Top. Catal., 2014, 57, 1015-1025.

[15] S. Sareen, V. Mutreja, S. Singh, B. Pal, RSC Adv., 2015, 5, 184-190.

[16] R. Zhang, D. Shi, Y. Zhao, B. Chen, J. Xue, X. Liang, Z. Lei, Catal. Today, 2011, 175, 26-33.

[17] L. Chmielarz, P. Kustrowski, R. Dziembaj, P. Cool, E. F. Vansant, Microporous Mesoporous Mater., 2010, 127, 133-141.

[18] H. Zhang, C. Tang, Y. Lv, C. Sun, F. Gao, L. Dong, Y. Chen, J. Colloid Interf. Sci., 2012, 380, 16-24.

[19] C. Ciotonea, B. Dragoi, A. Ungureanu, A. Chirieac, S. Petit, S. Royer, E. Dumitriu, Chem. Commun., 2013, 49, 7665-7667.

[20] S. Wang, W. Guo, H. Wang, L. Zhu, S. Yin, K. Qiu, New J. Chem., 2014, $38,2792-2800$.

[21] F. Li, L. Wang, X. Han, P. He, Y. Cao, H. Li, RSC Adv., 2016, 6, 4589445906.

[22] Q. Xin, A. Glisenti, C. Philippopoulos, E. Poulakis, M. Mertens, J. L. Nyalosaso, V. Meynen, P. Cool, Catalysts, 2016, 6, 164

[23] X. Zhong, J. Barbier Jr., D. Duprez, H. Zhang, S. Royer, Appl. Catal. B. 2012, 121-122, 123-134.

[24] A. Ungureanu, B. Dragoi, A. Chirieac, S. Royer, D. Duprez, E. Dumitriu, J. Mater. Chem., 2011, 21, 12529-12541.

[25] A. Ungureanu, B. Dragoi, A. Chirieac, C. Ciotonea, S. Royer, D. Duprez, A. S. Mamede, E. Dumitriu, ACS Appl. Mater. Interf., 2013, 5, 30103025.

[26] B. Dragoi, A. Ungureanu, A. Chirieac, V. Hulea, S. Royer, E. Dumitriu, Catal. Sci. Technol., 2013, 3, 2319-2329.

[27] A. Chirieac, B. Dragoi, A. Ungureanu, C. Ciotonea, I. Mazilu, S. Royer, A S. Mamede, E. Rombi, I. Ferino, E. Dumitriu, J. Catal., 2016, 339, 270283.

[28] C. Rudolf, I. Mazilu, A. Chirieac, B. Dragoi, F. Abi-Ghaida, A. Ungureanu, A. Mehdi, E. Dumitriu, Environ. Eng. Manag. J., 2015, 14, 399-408.

[29] C. Rudolf, F. Abi-Ghaida, B. Dragoi, A. Ungureanu, A. Mehdi, E. Dumitriu, Catal. Sci. Technol., 2015, 5, 3735-3745.

[30] B. Dragoi, I. Mazilu, A. Chirieac, C. Ciotonea, A. Ungureanu, E. Marceau, E. Dumitriu, S. Royer, Catal. Sci. Technol., 2017, 7, 5376-5385.

[31] P. Gallezot, D. Richard, Catal. Rev. Sci. Eng., 1998, 40, 81-126.

[32] P. Mäki-Arvela, J. Hájek, T. Salmi, D. Y. Murzin, Appl. Catal. A, 2005, 292, 1-49.

[33] A. Chambers, S. D. Jackson, D. Stirling, G. Webbz, J. Catal., 1997, 168, 301-314.

[34] A. J. Marchi, D. A. Gordo, A. F. Trasarti, C. R. Apesteguía, Appl. Catal. A., 2003, 249, 53-67.

[35] S. Valange, A. Derouault, J. Barrault, Z. Gabelica, J. Mol. Catal. A-Chem., 2005, 228, 155-266

[36] V. Gutierrez, A. Diez, M. Dennehy, M. A. Volpe, Microporous Mesoporous Mater., 2011, 141, 201-213.

[37] V. Gutierrez, M. Alvarez, M. A. Volpe, Appl. Catal., A., 2012, 413-414, 358-365.

[38] V. Gutierrez, M. Dennehy, A. Diez, M. A. Volpe, Appl. Catal., A., 2012 437-438, 72-78

[39] Z. Liu, Y. Yang, J. Mi, X. Tan, Y. Song, Catal. Commun., 2012, 21, 58-62.

[40] Y. Zheng, J. Liang, Y. Chen, Z. Liu, RSC Adv., 2014, 4, 41683- 41689.

[41] S. Handjani, E. Marceau, J. Blanchard, J.-M. Krafft, M. Che, P. MäkiArvela, N. Kumar, J. Wärna, D. Y. Murzin, J. Catal., 2011, 282, 228-236.

[42] S. Wu, Y. Han, Y.-C. Zou, J.-W. Song, L. Zhao, Y. Di, S.-Z. Liu, F.-S. Xiao, Chem. Mater. 2004, 16, 486-492.

[43] A. Ungureanu, B. Dragoi, V. Hulea, T. Cacciaguerra, D. Meloni, V. Solinas, E. Dumitriu, Microporous Mesoporous Mater., 2012, 163, 51-64.

[44] A. Yin, X. Guo, W.-L. Dai, K. Fan, J. Phys. Chem. C, 2010, 114, 85238532.

[45] A. Galarneau, H. Cambon, F. Di Renzo, F. Fajula, Langmuir, 2001, 17, 8328-8335. 
[46] F. Rouquerol, J. Rouquerol, K. Sing, Adsorption by Powders and Porous Solids: Principles, Methodology and Applications, Academic Press, London, 1999.

[47] N. Bejenaru, C. Lancelot, P. Blanchard, C. Lamonier, L. Rouleau, E. Payen, F. Dumeignil, S. Royer, Chem. Mater., 2009, 21, 522-533.

[48] S. Handjani, J. Blanchard, E. Marceau, M. Che, Microporous Mesoporous Mater., 2008, 116, 14-21.

[49] M. J. Orellana Rico, R. Moreno-Tost, A. Jiménez-López, E. RodríguezCastellón, R. Pereñíguez, A. Caballero, J. P. Holgado, Catal. Today, 2010, 158, 78-88.

[50] M. H. Nilsen, E. Antonakou, A. Bouzga, A. Lappas, K. Mathisen, M. Stöcker, Microporous Mesoporous Mater., 2007, 105, 189-203.

[51] J. F. Moulder, W. F. Stickle, P. E. Sobol, K. D. Bomben, Handbook of $X$ Ray Photoelectron Spectroscopy: A Reference Book of Standard Spectra for Identification and Interpretation of Xps Data, Physical Electronics, 1979.

[52] J. Ghijsen, L. H. Tjeng, J. van Elp, H. Eskes, J. Westerink, G. A. Sawatzky, M. T. Czyzyk, Phys. Rev. B: Condens. Matter., 1988, 38, 11322-11330.

[53] G. Avgouropoulos, T. loannides, Appl. Catal., B, 2006, 67, 1-11.

[54] K.-S. Lin, C.-Y. Pan, S. Chowdhury, W. Lu, C.-T. Yeh, Thin Solid Films, 2011, 519, 4681-4686.

[55] R. Bechara, A. Aboukaïs, J.-P. Bonnelle, J. Chem. Soc. Faraday Trans. 1993, 89, 1257-1262.

[56] S. Bennici, A. Gervasini, N. Ravasio, F. Zaccheria, J. Phys. Chem. B 2003, 107, 5168-5176.

[57] L. Qi, Q. Yu, Y. Dai, C. Tang, L. Liu, H. Zhang, F. Gao, L. Dong, Y. Chen, Appl. Catal., B, 2012, 119- 120, 308-320.

[58] C. He, Y. Yu, C. Chen, L. Yue, N. Qiao, Q. Shen, J. Chen, Z. Hao, RSC Adv., 2013, 3, 19639-19656.

[59] A. B. Dongil, B. Bachiller-Baeza, E. Castillejos, N. Escalona, A. GuerreroRuiz, I. Rodriguez-Ramos, Catal. Sci. Technol., 2016, 6, 6118-6127.

[60] G. Aguila, F. Gracia, P. Araya, Appl. Catal., A, 2008, 343, 16-24.

[61] A. Patel, P. Shukla, J. Chen, T. E. Rufford, S. Wang, V. Rudolph, Z. Zhu, Chem. Eng. Res. Des., 2015, 101, 27-43.

[62] W.-P. Dow, Y.-P. Wang, T.-J. Huang, Appl. Catal., A, 2000, 190, 25-34.

[63] S. Gentry, P. Walsh, J. Chem. Soc. Faraday Trans. I, 1982, 78, 15151523.

[64] W.-P. Dow, T.-J. Huang, Appl. Catal., A, 1996, 141, 17-29.

[65] L. Chen, T. Horiuchi, T. Osaki, T. Mori, Appl. Catal., B, 1999, 23, 259-269.

[66] A. Gervasini, S. Bennici, Appl. Catal., A, 2005, 281, 199-205.

[67] G. C. Chinchen, C. M. Hay, H. D. Vandervell, K. C. Waugh, J. Catal., 1987, 103, 79-86.

[68] G. K. Reddy, K. S. R. Rao, P. K. Rao, Catal. Lett., 1999, 59, 157-160.

[69] G. V. Sagar, P. V. R. Rao, C. S. Srikanth, K. V. R. Chary, J. Phys. Chem. $B, 2006,110,13881-13888$.

[70] A. B. Boffa, C. Lin, A. T. Bell, G. A. Somorjai, Catal. Lett., 1994, 27, 243249.

[71] M. Englisch, A. Jentys, J. A. Lercher, J. Catal., 1997, 166, 25-35.

[72] A. J. Plomp, D. M. P. van Asten, A. M. J. van der Eerden, P. Maki-Arvela, D. Y. Murzin, K. P. de Jonga and J. H. Bittera, J. Catal., 2009, 263, 146-154.

[73] D. Zhao, J. Feng, Q. Huo, N. Melosh, G. H. Fredrickson, B. F. Chmelka, G. D. Stucky, Science, 1998, 279, 548-552.

[74] Q. Yuan, A.-X. Yin, C. Luo, L.-D. Sun, Y.-W. Zhang, W.-T. Duan, H.-C. Liu, C.-H. Yan, J. Am. Chem. Soc., 2008, 130, 3465-3472.

[75] C. Ciotonea, I. Mazilu, B. Dragoi, C. Catrinescu, E. Dumitriu, A. Ungureanu, H. Alamdari, S. Petit, S. Royer, ChemNanoMat, 2017, 3 233-237.

[76] C. Ciotonea, B. Dragoi, A. Ungureanu, C. Catrinescu, S. Petit, H. Alamdari, E. Marceau, E. Dumitriu, S. Royer, Catal. Sci. Technol., 2017, 7, 5448-5456 
Entry for the Table of Contents (Please choose one layout)

Layout 1:

\section{FULL PAPER}

Thanks to $\mathrm{Al}$ incorporation, $\mathrm{Cu}$ is stabilized within the pores of Al-SBA15 ordered mesoporous system as highly dispersed nanoparticles, showing high catalytic activity and chemoselectivity towards cinnamyl alcohol (CNOL) in the liquid-phase hydrogenation of cinnamaldehyde (CNA)

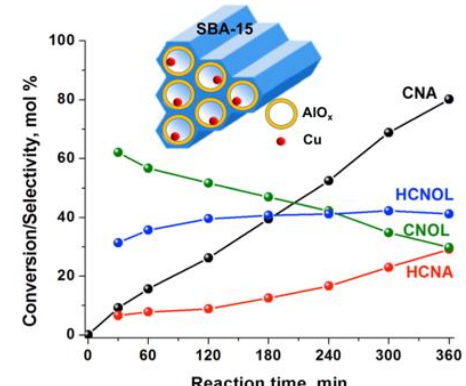

A. Ungureanu, ${ }^{*} A$, Chirieac, $C$. Ciotonea, I. Mazilu, C. Catrinescu, S. Petit, E. Marceau, * S. Royer, E. Dumitriu

Page No. - Page No.

Enhancement of copper dispersion and catalytic performances in the hydrogenation of cinnamaldehyde by incorporation of aluminium into mesoporous SBA-15 